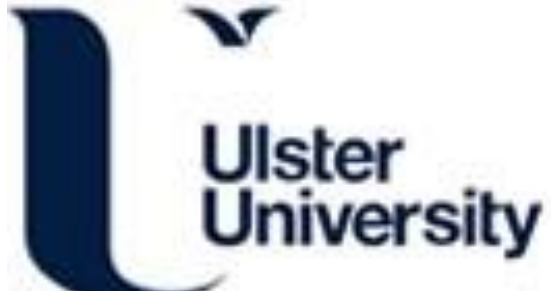

\section{A rewarding experience? Exploring how crowdfunding is affecting music industry business models}

Gamble, J., Brennan, M., \& McAdam, R. (2017). A rewarding experience? Exploring how crowdfunding is affecting music industry business models. Journal of Business Research, 70, 25-36. https://doi.org/10.1016/j.jbusres.2016.07.009

Link to publication record in Ulster University Research Portal

\section{Published in:}

Journal of Business Research

Publication Status:

Published (in print/issue): 01/01/2017

DOI:

10.1016/j.jbusres.2016.07.009

\section{Document Version}

Author Accepted version

\section{General rights}

Copyright for the publications made accessible via Ulster University's Research Portal is retained by the author(s) and / or other copyright owners and it is a condition of accessing these publications that users recognise and abide by the legal requirements associated with these rights.

\section{Take down policy}

The Research Portal is Ulster University's institutional repository that provides access to Ulster's research outputs. Every effort has been made to ensure that content in the Research Portal does not infringe any person's rights, or applicable UK laws. If you discover content in the Research Portal that you believe breaches copyright or violates any law, please contact pure-support@ulster.ac.uk. 


\title{
A rewarding experience? Exploring how crowdfunding is affecting music industry business models
}

\begin{abstract}
This paper provides an exploratory study of how rewards-based crowdfunding affects business model development for music industry artists, labels and live sector companies. The empirical methodology incorporated a qualitative, semi-structured, three-stage interview design with fifty seven senior executives from industry crowdfunding platforms and three stakeholder groups. The results and analysis cover new research ground and provide conceptual models to develop theoretical foundations for further research in this field. The findings indicate that the financial model benefits of crowdfunding for independent artists are dependent on fan base demographic variables relating to age group and genre due to sustained apprehension from younger audiences. Furthermore, major labels are now considering a more user-centric financial model as an innovation strategy, and the impact of crowdfunding on their marketing model may already be initiating its development in terms of creativity, strength and artist relations.
\end{abstract}

Keywords: rewards-based crowdfunding; business model; music industry; financial model; user-centric; innovation 


\section{Introduction}

This paper will explore the nature of how rewards-based crowdfunding affects business model (BM) development in the music industry (including both recorded and live music sectors). In this industry over $90 \%$ of organisations are comprised of fewer than 250 employees and changes in the innovation and BM landscape have been driven as much by start-ups as by the global corporations (IFPI, 2013). With regard to BMs, Bourreau et al. (2012) have expressed that "[v]ery few papers have taken a broader view, to analyse the effects of digitization on [music industry] business models" (p. 416). Lysonski and Durvasula (2008) have also stressed the need for more research into the music industry that would establish the practicability of different BMs. The recurring themes in these academic calls for research appear to be the need for a new industry-level BM or a combination of firm- or sector-level BMs for the music industry, with other scholars supporting these ideas as a means of pursuing ideals such as sustainable revenue (Parry et al., 2014a; Sirkeci and Magnúsdóttir, 2011) or the provision of attractive alternative options to illegal file-sharing (Papies et al., 2011).

Dewenter et al. (2012) have demonstrated in their research findings that music industry BMs which are integrated with consumer involvement through file sharing can result in both recorded and live sector benefits in terms of profitability and product variety. Consequently, they call for future research to further explore what they describe as 'richer models' for the industry. The current paper will endeavour to contribute to the contemporary academic research in this field by empirically exploring the development of new music industry BMs that are integrated with consumer involvement via rewardsbased crowdfunding.

Crowdfunding is a type of crowdsourcing in which an individual or enterprise seeks to accumulate the funds for a project or venture by reaching out to the general public 
and requesting individual donations that contribute towards a target financial goal. Unlike equity-based crowdfunding in which contributors essentially become stakeholders through angel investment and equity procurement, rewards-based crowdfunding is more commonplace, simplistic and popular with consumers, at least partly on account of the exposure gained by celebrity ventures, in addition to the proliferation of prominent platform websites. For instance, the Kickstarter platform (www.kickstarter.com) describes itself on its official website as a global community of over ten million people worldwide who have funded creative projects advertised through the website. The platform provides step-by-step guidance for building your project, getting feedback, launching the venture, tracking the funding progress and then facilitating the allocation of 'rewards' once the financial target has been accomplished. With the nature of rewardsbased crowdfunding, these 'rewards' to investors may take the form of discounted products/services relating to the crowdfunded venture or entry into a draw to win a valuable item (such as limited edition merchandise or signed memorabilia) or experience related to the venture.

Rewards-based crowdfunding is growing in the variety of sectors to which it is applied (e.g., music, sports, video games, education, retail) (Agrawal et al., 2011). In fact, statistics on the Kickstarter website illustrate that the sector reach of crowdfunding now extends to more obscure industries such as crafts, fashion, food and publishing. As each industry exhibits a potentially new range of available rewards for willing consumers, the possibilities of the platform are only limited by the imagination and the attention spans of the contributors. However, as the rewards-based system has been in existence since Marillion's 1997 album and crowdfunding revenue figures are still continuing to rise, the indications are that this will remain a high growth sector for the foreseeable future. Like most technologically-driven industry sectors, the crowdfunding domain is an oligopolistic market that is dominated by a few key players. Aside from the aforementioned 
Kickstarter, the platforms GoFundMe and Indiegogo are also ranked in the top 3 of rewards-based crowdfunding platforms according to the www.crowdfunding.com website (based on independent traffic data from digital analytics companies Alexa and Compete).

Zheng et al. (2014) recently advised that crowdfunding has developed into a prevalent practice within the music industry on account of fan involvement in the creative side of music production. This statement is compounded with official statistics on the Kickstarter website that indicate that 46,251 music crowdfunding projects have been launched through their platform since 2009. In spite of this, few studies have specifically focused on how this growing phenomenon is shaping the business modelling of key stakeholders within the industry. As a direct result of this, there have been recent suggestions that there exists a lack of clarity of how exactly crowdfunding might "change the game' for new ventures that seek financing. The current study will address this gap in research and knowledge by investigating how rewards-based crowdfunding is affecting both new and established industry players in order to determine the practical implications of these new BM developments across different industry sectors.

The paper will be structured as follows. Section 2 will provide a brief overview of how a BM is conceptualised and constructed. It will then review the academic literature in relation to the contemporary challenges associated with music industry BMs and the emergence of new models within the industry. The literature on music crowdfunding will then be reviewed from the context of BM implications. The theoretical development of the paper will then be stated in which research questions will be proposed. Section 3 will present the research methodology in which the methodological position and design are stated and the data analysis approach is justified and detailed. Section 4 will present the results and analysis of the three interview stages in terms of how they correlate to the research questions and the existing literature. Section 5 will then draw logical conclusions 
from the findings and demonstrate the contribution of the current study to theory, practice and future research.

\section{Literature review}

\section{$2.1 \quad$ Defining a business model}

Zott and Amit (2010) define a BM from an entrepreneurial management perspective as "a template of how a firm conducts business, how it delivers value to stakeholders $[\ldots]$ and how it links factor and product markets" (p. 222). This definition perceives the BM both in terms of its organisational application as well as its functions; Demil and Lecocq (2010) conceptualise it instead from a more philosophical perspective by suggesting that it constitutes the way in which an organisation operates with sustainability in mind. They later elaborate on this statement by claiming that it is also a snapshot of a given moment in time for the organisation. However, Cavalcante et al. (2011) advise against the snapshot approach as a static representation of the BM and argue for the importance of BM change through the identification of its boundaries and mechanisms. Al-Debei and Avison (2010) also define the BM with time-frame considerations by suggesting that it can be conceived as an abstract representation of organisational arrangements - designed and developed both presently and in the future. Doz and Kosonen (2010) provide a way of observing the dichotomous dimensions of the BM concept by acknowledging the prospect of defining it in terms of either an objective or subjective approach. From the objective perspective they define it as a set of structured and interdependent operational relationships with both internal organisational units and external stakeholders. From a subjective point of view they define it as the representation of the mechanisms through which these relationships are implemented in the external environment. 
It is perhaps the objective perspective of the BM concept that is most readily accepted throughout the extant literature, with Mason and Spring (2011) proposing that this conceptualisation of the BM represents a 'truth' by describing how the business works. However, if the subjective perception of the BM relates to its actuality in implementing this business know-how in practice then would it not be logically accepted in the literature as the most influential approach for business practitioners? George and Bock (2011) have demonstrated opposition to this standpoint by arguing that "[u]nderstanding BMs as a form of subjective and often retroactively adjudicated narration does not match practitioner language" (p. 98). However, their arguments may perhaps be influenced by their academic backgrounds and do not necessarily represent the true practitioner viewpoint on this issue.

With the above discussion in mind, below is a summary of some potential defining characteristics that may be inclusive of a generic BM:

- It is a visual means consisting of a template, description or representation (Al-Debei and Avison, 2010; Doz and Kosonen, 2010; Sandberg et al., 2011; Shafer et al., 2005; Zott and Amit, 2010);

- Its firm-related objectives include conceptualisation, summarising and understanding (Al-Debei and Avison, 2010; McGrath, 2010);

- It incorporates the complex network of internal and external component relationships (Chesbrough, 2006; Demil and Lecocq, 2010; Doz and Kosonen, 2010);

- It considers the firm from the context of both the present and future tense (Al-Debei and Avison, 2010; Doganova and Eyquem-Renault, 2009); and

- It ascertains the firm's potential in relation to value goal opportunities through strategic implementation (George and Bock, 2011; Kallio et al., 2006; Shafer et al., 2005; Zott and Amit, 2010). 
The next sub-section will take this working definition of a generic BM and apply it to the chosen industry context in order to review the current BM landscape of the music industry, what are the current associated challenges and which types of BMs are the most appropriate to the current study.

\subsection{Current business models in the music industry}

The majority of the management literature that discusses redistribution of music industry BMs has concentrated on revenue models, with suggestions that this aspect depends on a number of variables including network support approaches (Generator, 2011) or the quality of copyright protection (Teece, 2010). However, it is advisable that it is dependent on the preferences of the consumer, as it has been noted in the literature that consumer payment inclinations over time are leaning more towards tiered imbursement plans (from freemium to premium) for streaming and subscription models and less towards the a-lacarte download to own revenue model. Hence, revenue streams are diversifying to incorporate other sectors of the industry such as live events, as Arewa (2010) acknowledges that "[u]nder existing music industry business models, top popular musicians actually earn far more from concert ticket sales than from record sales royalties" (p. 459). With this insight into how revenue streams in general are diffusing into the live sector of the music industry, the companies which operate within this area may therefore represent an appropriate stakeholder group from which to specifically and empirically explore one particular revenue model innovation such as crowdfunding.

The next sub-sections will review the literature on the challenges associated with contemporary music industry BMs and how some revenue model innovations such as crowdfunding may be influencing BMs within the industry. 


\subsection{Contemporary challenges for music industry business models}

The a-la-carte legal download revenue model pioneered by Apple at the start of the digital revolution arguably drove consumers to devalue the legal music content. At the same time it arguably incited the industry to constantly re-adapt its BM to create value for the consumer through alternative distribution channels (Parry et al., 2014b). These disruptive innovations to existing distribution channels have undoubtedly brought uncertainty regarding the sustainability of newly formulated industry BMs after any initial upwelling of interest in their originality (CCS, 2011). However, Lincoff (2008) also advises that this re-adaption of industry-sanctioned BMs may in itself prove problematic as he describes the associated license fees to the rights holders for these BMs as "so high as to limit the number of services that can possibly participate in the lawful marketplace" (p. 22).

Another current challenge facing the industry is the attempt to regain control and authority by way of the constant litigation and legal disputes that the industry has launched against not only some of the unlicensed digital music services but also the music users. Specifically, some of the major record labels have opted for legal action against user-driven innovations in music access and pricing models (Casadesus-Masanell and Hervas-Drane, 2010; Kunze and Mai, 2007; Oestreicher and Kuzma, 2009). Essentially, these user innovations may prove problematic as once consumer creativity profoundly affects the original innovation the IP rights of the firm may become unclear with regard to technology licensing and patent approval (Harhoff et al., 2003; Herstatt and Schweisfurth, 2014; Lüthje et al., 2005; von Hippel, 2007). Due to the shifting dynamics of the music industry and the arguable re-positioning of the role of the major record labels within the market, they may represent a stakeholder group from which to explore the extent to which they are approaching changes to their own financial model and becoming more accepting towards consumer involvement in the process. 
In competitive markets such as the digital music market, failures to innovate BMs will not only lead to the demise of certain key industry players on account of some of the current BM issues, but will also lead to the emergence of new and innovative BMs for others. This viewpoint is supported by scholars who suggest that some music artists have responded to industry failures to adopt new models by experimenting with new models themselves (Arewa, 2010; Ericsson, 2010). With this alleged innovativeness on the part of independent artists in terms of willingness to experiment with new BMs, combined with the earlier literary suggestion that they are now beginning to integrate new technologically-focused elements into the core structure of their own BM, they may represent a suitable stakeholder group for which the empirical data collection of the present study could be aimed.

\subsection{Developing new business models for the music industry}

The literature provides suggestions and advice as to which elements or features should be most prominent in new music industry BMs. These suggestions include lower price margins on digital music downloads (Lysonski and Durvasula, 2008), a re-engineered value chain (Oestreicher and Kuzma, 2009), co-operative arrangements for the youth demographic (Lysonski and Durvasula, 2008) and a sustainable revenue stream (Parry et al., 2014a; Sirkeci and Magnúsdóttir, 2011; Styvén, 2010). Kappel (2009) suggests that "[t]he new model for the recording industry may be 'no one model' at all. Artists will claw, scratch, bite, and kick their way into the industry" (p. 385). One means he mentions is the aspect of incorporating crowdfunding into their BM as a method of co-creation of value (and revenue) with the music users. The concept of rewards-based crowdfunding, whereby incentives are offered in exchange for financial contributions towards the development and production of an idea, product or service, is a relatively contemporary phenomenon in business and management fields. Despite its origins lying with the 
precursor of 'collective fundraising' in the $17^{\text {th }}$ century, the modern concept of crowdfunding only emerged in 1997 with the campaigns of the British music band Marillion; Figure 1 below illustrates the short, yet influential, evolution of the rise of crowdfunding and how it transcends various industries and countries. The next section will now consider its application to - and impact on - BMs specifically within the music industry.

[Figure 1 here]

\subsection{How crowdfunding is affecting the music industry}

There is very limited but interesting discussion of music industry crowdfunding in the peer-reviewed academic literature. For example, some authors have alluded to the prospect that crowdfunding can help artists overcome financial limitations (Agrawal et al., 2011). According to Kappel (2009), crowdfunding models are more sustainable than other conventional revenue streams. This is allegedly on account of a more balanced engagement level from consumers and the artist because "fans become literally invested in the success of their artists" (p. 376). The Kickerstarter statistics would certainly appear to reflect this as music crowdfunding projects through that platform have generated a total of \$155.76 million (from a target of \$171.62 million) since it was launched in 2009 . Kappel (2009) also suggests that crowdfunding models, if successful, could potentially counteract the devaluing of all recorded music - arguably one of the most prominent issues currently facing the music industry today. In terms of how specifically this perception shift will occur, he expressed that it may be realised through exposing the consumers to marketplace realities and debunking the hostile mentality between consumers and the industry. It may also be perceived as a way for the industry to (attempt to) regain control of revenue streams as, although the amount raised is unpredictable and 
subject to circumstantial risks, the consumers' involvement and control is limited to financial contributions and the loyalty rewards may be sufficient to satisfy the more affluent music fans. However, Ordanini et al. (2011) maintain that crowdfunding models do empower the fans as well as the artists in a global community, and suggest that loyalty rewards may extend beyond mere music content or merchandise to a share of the revenue generated by the artist. This approach could potentially offset the social preferences relating to apprehensions for reciprocity that may constitute a driver for consumers who engage in crowdfunding activities (Regner and Barria, 2009). In addition to consumer motivations, other authors have raised concerns over the negative, de-motivational connotations associated with failed or sub-standard crowdfunding projects (Buff and Alhadeff, 2013).

The limited literature discussion on crowdfunding within the music industry has exhibited much ambiguity about which specific sectors, areas of players within the industry are being affected by crowdfunding in terms of BM development. Through the preceding sub-sections, it has emerged through the broader review of music industry BMs that the independent artists, major record labels and live sector firms may represent key stakeholders from which to focus the empirical exploration of this research topic. The next sub-section will consider the state of theoretical development in the field of music industry crowdfunding and propose specific research questions to guide the data collection stage.

\subsection{Theoretical development}

The initial literature reviews above have revealed a lack of theoretical development in relation to how crowdfunding is effectively re-shaping the music industry in terms of industry stakeholders, BMs and sector landscapes. Any relevant discussion appears to be based on speculation as opposed to qualitative, empirical investigation and analysis. 
There is somewhat ambiguous and descriptive discussion of how crowdfunding applications may be influencing the practices of distinct yet correlational stakeholders of artists, firms and end consumers. This accentuates how any initial implications of these aspects that were suggested in the current literature are substantially lacking in terms of empirical evidence and how they are directly and specifically affected in terms of BM development. The discussion does provide some tentative suggestions of associated BM impacts relating to finance (in terms of sustainability, re-valuation, control strategies and generated shared revenue). However, the lack of in-depth analytical discussion, empirical exploration or clarification of operation model crossover implications necessitates significantly more theoretical development of these concepts.

An initial review of crowdfunding literature from a non-music industry context provides substantially more theoretical development in terms of the influence of crowdfunding on the current business landscape. For instance, Belleflamme et al. (2013) suggest that crowdfunding involving pre-order elements has associated advantages in terms of how advanced sales help to identify and reward the most proactive consumers and thus to practise price discrimination. However, they also suggest that a key disadvantage lies in how these pre-sales must be of an amount that covers the start-up capital requirement, thus potentially restricting lucrative price discrimination. They then develop a theoretical framework for crowdfunding in which they hypothesise that, although it has the potential to enhance profits by attaining a larger portion of the consumer surplus, the price discrimination strategy may become distorted due to the constraints associated with the initial capital to be raised. Lehner (2013) also suggests that the success of crowdfunding is dependent on the strategic adaptation of industry models to facilitate communication means as an alternative to the inclusion of end-consumers in the decision-making process. He also alluded to the possibility that the impact of largescale crowdfunding can have non-financial BM implications such as elevated levels of 
attractiveness of the company in terms of future investment and employment, in addition to what he describes as "a refined outlook of what is really needed through the feedback of the many" (p. 300).

Although the conceptual models of crowdfunding as proposed by the above authors are not fundamentally applicable to the unique and interconnected business landscape of the music industry and the relationships that exist between its stakeholder groups, nevertheless the theoretical underpinnings of the above discussion may have invaluable implications if used as the foundation from which to empirically explore the chosen industry context of the current study. For example, the work by Belleflamme et al. (2013) as well as Griffin (2012) highlights the significance of ascertaining the impacts - both positive and negative - that crowdfunding is having on the financial model of specific industry stakeholders and what are their related approaches to this kind of BM development. One isolated statement in the literature by Kappel (2009) has suggested that crowdfunding may prove to be more sustainable than alternative revenue models for artists. In order to contribute towards the theoretical development of this topic, the current study will explore not only the validity of this statement but also the holistic implications for this and the other identified stakeholder groups within the music industry. Consequently, the first research question to be empirically investigated will be:

\section{Research Question 1: How is crowdfunding in the music industry affecting the ways in which key stakeholder groups approach and develop their financial models?}

The theoretical contribution by Lehner (2013) addressed the concept of how the impact of crowdfunding may actually have non-financial BM implications that can prove beneficial to the industry company in terms of its attractiveness and employee quality. In the music industry literature, Zheng et al. (2014) raised the possibility that crowdfunding 
has become prevalent throughout the industry at least partly due to fan involvement in the creative side of music production. This viewpoint echoes a statement by DubossonTorbay et al. (2002) that cost/revenue models can influence other BMs related to customer relationships or product/service production. Therefore, in order to make a theoretical contribution to this topic, the current study could also explore how crowdfunding is affecting the identified stakeholder groups in terms of other BMs such as marketing and production models. Consequently, the second research question to be empirically investigated will be:

\section{Research question 2: What are the crossover implications of these consumer-driven financial model developments on other associated business models of the stakeholders?}

Lehner (2013) also proposed in his theoretical discussion that the success of crowdfunding may be reliant on the strategic adaptation of industry models to facilitate certain key attributes such as communication means. Incidentally, Kappel (2009) advised that the reconfiguration of the balance of engagement levels between artists and fans could ensure the sustainability of crowdfunding. Therefore, the current study could address the question of what other BM adaptations may facilitate crowdfunding success within the music industry in the medium to long term - this may be especially pertinent when one considers both the constantly shifting business landscape of the industry and the number of stakeholders who have yet to strategically align their BM operations to integrate crowdfunding elements. Consequently, the third research questions to be empirically investigated will be: 
Research question 3: What future adaptation strategies should these industry stakeholders, organisations or sectors take in order to maximise the efficiency of their user-centric business model innovations?

By conducting an exploratory study which addresses this emerging field of crowdfunding within the music industry, this paper will aim to make a valuable contribution to theoretical development in this field by covering new research ground and facilitating a superior clarity and configuration of theory, knowledge and understanding. This approach could potentially initiate more focussed and germane additional empirical research to concentrate on the critical issues and challenges that have been overlooked in the research so far. It could also result in an improved perception of crowdfunding as a justifiable and essential business strategy for companies - both internal and external to the creative industries - and not exclusively an academic exercise. It may consequently have repercussions at the industry and policy level.

\section{Research Methodology}

\subsection{Methodological position and design}

It was decided to adopt an interpretive epistemological approach to the research methodology of this study due to the exploratory and emergent nature of the phenomena under consideration, as consistent with the philosophical positions of other scholars (Grant et al., 2012; Qu and Dumay, 2011). For instance, Allard-Poesi (2005) provided clarity on the ontological position of an interpretive epistemology by stating that it seeks 
to develop and objective social science of subjectivity. Other key academics have emphasised that, on account of how interpretivism epitomises an ontological reality where knowledge is derived from socially constructed meanings or consciousness (Cardoso and Ramos, 2012; Rowlands, 2005). Harris (2000) crystallises these paradigmatic anomalies by stating that " $[\mathrm{t}]$ he interpretative requirement is to capture the complexity and subjectivity inherent within user-centric innovation in order to help build and refine theoretical propositions and to enrich findings" (p. 756). Based on the above discussion points, it was therefore concluded that, due to the exploratory and opinionbased nature of the research aim of the current study, an interpretive epistemology would be adopted.

Based on the interpretive and exploratory nature of the research area, (Grant et al., 2012; Qu and Dumay, 2011), it was decided to adopt a multi-stage interview-based research method. In terms of the nature of the population of interviewee candidates, this study - like most music industry studies - was not geographically limited due to the social and online reach of the global music industry (Chaney, 2012; Choi and Burnes, 2013; Gamble and Gilmore, 2013; Izvercian and Alina Seran, 2013; Power and Hallencreutz, 2007; Soriano et al., 2008; Warr and Goode, 2011). Therefore, candidates from around the world were considered suitable representatives for the study if they either held a senior management position in their organisation (the vast majority were either the company CEO or Director) or substantial relevant experience/knowledge in the field of the interview stage.

Stage One of the interview design consisted of thirty four interviews with music industry professionals with an expertise of consumer involvement - either through crowdfunding or other interactions. Stage Two provided more focussed and in-depth study by conducting interviews with five representatives from each of three relevant industry stakeholder groups based on issues that emerged from the Stage One interview 
data. Stage Three was based on addressing follow-up questions with eight select interviewees from Stage One, in order to ascertain final insights that reflect on their previous statements as well as the responses from the Stage Two interviewees.

Eighty eight potential Stage One interview candidates were identified and their contact details were documented. These candidates can be broadly demarcated into three categories: senior managers of music industry firms that offer services to facilitate consumer involvement and contributions (including crowdfunding platforms, fan-run record labels, direct-to-fan platforms, interactive music creation apps, fan-interaction marketing, consumer-licensed soundtracks and others); industry professionals or academics who research or write on the phenomena of consumer involvement in the music industry; and other individuals who have an expertise in the field of music industry consumer interactions through industry experience (such as members of world-renowned bands who have a history of involving their fans and industry practitioners who have worked closely with consumers over the years). The final interview count for Stage One of the empirical research stage was thirty four semi-structured interviews.

The analysis of the Stage One interview findings confirmed the appropriateness of the three identified industry stakeholder groups that were then the subject of more focused and in-depth study in Stage Two of the interviews. For the first stakeholder group of independent music artists, it was decided that artist managers would constitute the most appropriate choice for these interviews for two reasons. The first reason was that they work closely with artists and therefore constitute a representative voice for expressing views on behalf of the artists. The second reason is that some artists may be unwilling or unable to answer questions focused on the business and management aspect of the music industry; this decision was corroborated by previous research by the writers in which they discovered that many artists struggled to vernacularise any non-creative aspects of their $\mathrm{BM}$ as this side of their career was entirely operated by their management. Artist 
managers possess sufficient industry knowledge and expertise to adequately generate high quality interview data from the questions, and as they are often either musicians themselves or have a history of liaising closely with musicians, their understandings of the music industry often transcend creative and business perspectives. The second stakeholder group was live sector firms and this would entail speaking with senior executives from a range of companies that operate within the live sector. The third stakeholder group was major record labels and, again, this would involve speaking with senior managers within these global corporations. The final interview count for Stage Two of the empirical research stage was fifteen semi-structured interviews - these consisted of interviews with five representatives from each of the three stakeholder groups.

Stage Three of the empirical research design consisted of follow-up interviews with a select few of the Stage One interviewees whose original views had been most relevant to both the two research questions of the study and the subsequent Stage Two statements. The purpose of this interview stage was therefore to inform them of Stage Two interviewee responses to their initial statements and to request further insights or clarification. The target candidates for this stage of the research were 10 of the Stage One interviewees. The final interview count for Stage Three was eight in-depth interviews.

\subsection{Data analysis}

At each stage of the interview process the interview framework included an analysis phase in which it was necessary to implement an arbitrarily defined analysis framework. A number of analytical considerations were developed; the first related to which analysis approach to adopt. Knox (2003) offered a distinction between inductive and deductive analytical approaches whilst simultaneously advocating the significance of the decision between the two approaches. He described an inductive approach as one in which "you 
would collect data and develop theory as a result of your data analysis is paramount" (p. 122). Due to the exploratory nature of the current study, as well as the fragmented and scarce knowledge surrounding the research aim and questions, it was most appropriate to analyse the interview data using an inductive approach in order to develop theoretical foundations.

The second analytical consideration referred to the coding approach to be adopted. DeCuir-Gumby et al. (2011) suggested three distinct coding approaches to analysis; these consist of data-driven approaches, theory-driven approaches and structural approaches. As it was decided above that the analysis approach for the current study will be inductive and theory-building, this precluded the option of adopting a theory-driven coding approach. Furthermore, as the research aim and questions are guided by minimal previous research and literature discussion, the strict adherence of codes to these questions as akin to a structural coding approach may not prove to be the most logical choice for maximising high-quality analysis of the interview data. The data-driven approach proposed by DeCuir-Gumby et al. (2011), in which they describe the codes as emerging from the raw interview data, was therefore the most appropriate and efficient for this study.

The third consideration was the analysis technique. Leech and Onwuegbuzie (2007) describe and compare seven distinct techniques for analysing data. Due to the exploratory and multi-faceted nature of the current study, as well as the anticipated richness of the interview data due to the scale and depth of the qualitative interview data, some of these techniques would therefore be unsuitable for this study. According to the views of Leech and Onwuegbuzie (2007), constant comparative analysis is utilised in order to discover underlying themes from research data. This appeared to initially adhere to the decisions made above to incorporate an inductive analysis approach and a datadriven coding approach. In terms of contextual application, this technique is especially 
applicable to qualitative research studies as it uses the entire data set and it was originally devised to analyse multiple-stage data. All of these contextual aspects were applicable to the current study; therefore it was decided that constant comparative analysis was the analysis technique to be utilised in the three stages of this interview research design.

\section{Results and discussion}

The interviewees cited in this section have been anonymised, with their names replaced by identifier labels. Each label consists of a code denoting the interview stage (S1, S2 or S3) followed by two randomly assigned letters.

\subsection{Impact of crowdfunding on artists' business models}

The first key sub-theme to emerge from the Stage One interview data related to the freedoms associated with BM restructuring that artists may experience from choosing to use crowdfunding platforms. S1AW - who had over four years' crowdfunding experience - cited freedoms to allocate crowdfunding capital as they see fit as the artists do not have to share their proceeds with the label. This viewpoint reflects a statement in the academic literature in which Agrawal et al. (2011) commented that crowdfunding can help artists to "relieve cash constraints" (p. 16). This sub-theme was also reiterated in the Stage Three follow-up interviews by S1RG who had over two years' live crowdfunding experience. He provided an example of a famous band that left their label in favour of crowdfunding and found that for the first time they were able to achieve significant financial success. This viewpoint is potentially significant as it demonstrates an insight into how crowdfunding-integrated financial models for artists benefit them in unusual ways. For instance, although crowdfunding generally does not generate profits for the artists' financial model as their budget is normally only higher than the target capital in order to take into account credit card commissions, taxes and other contingency costs, 
nevertheless they can accrue higher funds for projects due to bypassing label commissions and therefore can achieve financial success indirectly as a result of superior product/service offerings.

Another key sub-theme to emerge from the Stage One interview data concerned creative freedom for the production model of artists. S1FG - the CEO of a start-up where consumers contribute to A\&R - suggested that crowdfunding also provides artists with "a clean slate in which to produce the music they want to make" (i.e. without any label regulations or restrictions) and he believed that this will result in superior music outputs. This viewpoint is supported in the academic literature by Agrawal et al. (2011) who commented that crowdfunding facilitates the creation of a market for the artist's "ideas, vision and future intellectual property" (p. 16). In his Stage Three follow-up interview, S1RG also addressed this aspect of crowdfunding facilitating creative freedom for the artist by suggesting that it can help them in terms of their marketing model by leveraging their brand and achieving previously unachievable goals such as live events or tours. This viewpoint was reflected by S1JF - who had over three years' experience of consumerdriven interactive marketing. He also suggested that crowdfunding can financially empower artists to cover new creative ground by going on tour for the first time.

In the Stage One interviews, S1MP and S1EO - who had two and one year's crowdfunding experience respectively - introduced the aspects of speed and longevity into the production model implications of crowdfunding by suggesting that it can enable artists to "produce quality output much sooner on in their careers" than they would have been able to without crowdfunding. This statement appears to support a recent academic literature article by Agrawal et al. (2011) that claims that "most [artists who participate in crowdfunding] are young, have limited reputations as artists or entrepreneurs, and appear to have minimal resources" (p. 1). S1EO also suggested that early career crowdfunding increases engagement levels that benefit both the consumers and the artist 
in terms of their marketing model. These statements add to the academic literature that only acknowledges the correlation between early career artists and crowdfunding and does not cite any themes relating to speed, longevity or engagement levels (Agrawal et al., 2011).

The Stage Two interviews with the artist managers also produced themes relating to fan base development or the sustainability impact that crowdfunding may have on artists' marketing models - an aspect that potentially resolves the issue of direct revenue instability with current BMs as proposed in the industry report literature (Arts Council, 2010). S2AK - who had two years' experience of managing artists - supplemented the engagement level theme from S1EO by suggesting that crowdfunding, if executed correctly, can transcend into an interpersonal relationship with associated positive perceptions of both interaction and sharing gestures, as opposed to the negative perceptions of financial demands. This point is potentially significant for illustrating how artists can benefit from user-centric financial models both in terms of direct revenue instability resolution as well as crossover marketing model implications.

The theme of ethical perceptions of crowdfunding, and how it can affect fan relations in different ways, was discussed throughout all three interview stages as well as in the literature. S2NP - who had over eight years' experience of managing artists but has not used crowdfunding - argued that it can exacerbate negative perceptions due to the financial demand aspect and that it can result in damaging fan relationships if they fail to deliver on the pledge. This latter facet is advocated by Buff and Alhadeff (2013) who analysed one hundred music crowdfunding campaigns on Kickstarter and stated that “non-fulfilment, or less-than-par fulfilment, jeopardizes the image of artists, and makes them lose credibility with fans" (p. 29).

The other feature of negative perceptions due to the financial demands on the consumers, which was proposed by the artist manager S2NP in her Stage Two interview, 
was challenged during the follow-up interviews by S1RG - who had over three years' experience as a music crowdfunding platform. He strongly maintained that positive perceptions from the consumers have driven and enhanced the sustainability of artist careers. His experience in this field, combined with the specific example he provided of an artist who achieved success only after leaving their label management and embracing crowdfunding, confirms his justifications whilst challenging a suggestion in the music industry report literature that "[w]ithout these [management] skills, any business model will find it hard to sustain itself after the initial surge of interest in a new product" (CCS, 2011, p. 13).

In Stage One, S1MP - who had over two years' experience in tour-based crowdfunding - stated that it is not significant compared to other types of music industry crowdfunding, but that it would develop on account of artists' need for touring where their fans are located. He therefore believed that financial motivations for touring revenue will drive development for the artists, while the geographic locality of the crowdfunded events will motivate financial contributions from the fans. Despite a suggestion to the contrary by another less informed interviewee, this statement provides an insight into how crowdfunded tour events may represent opportunities for financial sustainability from crowdfunding. Furthermore, two of the interviewees expressed that live event crowdfunding in general may mitigate the risk of artists enduring financial loss on poorly attended events; consequently these findings demonstrate that this sector may represent a high-growth opportunity area for future artist crowdfunding initiatives.

In the Stage One interviews, S1PA hypothesised that if too many artists take advantage of the platform by not delivering it could have repercussions for the sustainability of the crowdfunding model itself due to a lack of consumer confidence. Another interviewee, S1AM, also cited the issue of artists taking advantage but provided the perspective of the consumers being manipulated on account of their increasingly 
young age and associated immaturity with financial management. Although neither of these interviewees had personal experience in music crowdfunding, their viewpoints nevertheless raise significant points regarding how ethical exploitation from artists can lead to negative consequences for not only the artist's marketing model and career building but also for the sustainability of crowdfunding itself.

S2JT - who had over twenty years' experience of working with artists in various capacities - provided in his Stage Two interview a logical and concise perspective on the importance of working on fan base development prior to instigation of crowdfunding platforms. His rationale was based on the notion of popularity in which he discussed how early stage artists who lack a support group of fans will struggle to reach crowdfunding goals. This viewpoint echoed another by S1MK who stated that the vast majority of music crowdfunding projects do not reach their goals. Although strictly not true (The Kickstarter website provides statistics demonstrating a success rate of $50.23 \%$ - the fourth highest category success rate and $15 \%$ higher than the total average), it is evident that the milestone-orientated funding purposes of rewards-based crowdfunding do expose ventures to potential failure. Thus, the statement by S1MK corroborates the significance of a balance between career stage and fan base development as a dependency factor for how crowdfunding can not only succeed but also positively affect an artist's career.

Another theme that was raised through the three interview stages related to dependency factors for positive impacts on the artists BMs. In Stage One, S1PS advised that in order to maximise the innovative potential for artists using crowdfunding they must also possess the skills and abilities to manage related business activities such as PR and marketing. S1TS reflected this viewpoint and extended it to also include end-sales taxes associated with crowdfunding - which she described as very complicated for artists who are not conversant with their own financial model. These statements are supported by Buff and Alhadeff (2013) who provide specific support for the financial 
knowledgeable argument from S1TS by emphasising the importance of budgeting strategies for artists wishing to benefit from crowdfunding campaigns.

In the Stage Two interviews, S2JW suggested that the innovation opportunities associated with crowdfunding were actually dependent on the connectedness of social media and internet technologies as well as brand partnerships. S2AK also suggested that fan base demographics constituted another dependency factor for how crowdfunding is affecting the artists in terms of their marketing model. The two variables he cited were age group - in which he stated that young children would not be favourable to the concept - and genre preferences - in which he stated that fans of rap or hip hop would be apprehensive of crowdfunding as it would fall outside the 'norms' of their genres.

In Stage Two, S2CC - who has over fifteen years' experience in various areas of the live music sector in Spain - discussed the revenue generation prospects of live music crowdfunding. He acknowledged the potential of crowdfunding but emphasised the challenges of building a large enough network of fan-investors to maintain a sustainable revenue model. His advice was to work with already existing networks to increase time and work efficiency. This statement echoes and advances the views expressed in an industry report by Generator (2011) that advocates support network approaches to enhance revenue generation in the music industry. The statement also challenges the argument made by Kappel (2009) that crowdfunding would necessarily offer greater sustainability for artists in comparison with alternative financial models.

\subsection{Impact of crowdfunding on major labels' business models}

In terms of how crowdfunding is affecting the BMs of the major record labels, the results only refer to their marketing model. This is because crowdfunding is not applicable to their own financial model as their income generation is derived from their global publishing, licensing and royalty payments. Furthermore, as they do not produce music 
or music-related content themselves they do not have a production model as such. Regarding the effect on their marketing model, S1RG - who had over two years' crowdfunding experience - argued in his Stage One interview that the major labels are having to re-think their relationships with artists on account of the rising instances of "bands crowdfunding just to get away from the label." Two of the Stage One interviewees suggested that crowdfunding is having disruptive ramifications on major label marketing models. S1PA stated in his interview that the rise in crowdfunding is forcing the major labels to "get more creative with their marketing services", whereas S1MM described the major labels as essentially marketing vehicles and suggested that crowdfunding has forced the labels to play to these strengths. These viewpoints are potentially significant as they suggest $\mathrm{BM}$ crossover implications as crowdfunding is affecting the labels through involuntary adaptation of their marketing model to become more creative, strong and artist-friendly.

As a summary of the above sub-section, Figure 2 below has been formulated to depict the ways in which rewards-based crowdfunding has impacted upon the financial model of the artist and major label stakeholder groups. The crossover implications of the impacts on the financial artist model and other BMs for the artist and label stakeholders, as depicted by the direction of influence arrows in the diagram, are potentially significant as they reflect and expand on the views expressed by Dubosson-Torbay et al. (2002) that cost/revenue aspects of the financial dimension of a BM framework impinge upon other framework components related to product/service production and customer relationship capital.

[Figure 2 here] 
The next theme to be discussed throughout the three interview stages and the academic literature is the extent to which the major labels are considering or implementing crowdfunding adoption strategies into their own BMs. In the Stage One interviews, S1WS asserted that the labels may use crowdfunding due to its low risk factor. This viewpoint is reflected by Bannerman (2013) who recently claimed that it can even be used to mitigate record label risk by "individualizing and distributing risk away from the organizations that traditionally helped to absorb that risk" (p. 29). In the Stage Three follow-up interviews, S1FG appeared to support this prospect of the major labels adopting crowdfunding as a risk mitigation strategy. He stated that their increasing openness is due to their acknowledgement of artist preferences towards crowdfunding and their wish to sign artists who are satisfied. This statement reflects the interviewee's opinion that the major labels have expressed concern regarding crowdfunding, and that they may ultimately have decided that there are fewer risks associated with adopting it than there would be from not adopting.

S1RM, who had over four years' experience of crowdfunding, acknowledged a recent collaboration deal signed between the crowdfunding platform PledgeMusic and major record labels and predicted that this contract is the beginning of a revolution towards a new movement of emerging crowdfunding-powered record labels. This prediction reflected the viewpoint of S1WS who suggested that major record label adoption of crowdfunding into their $\mathrm{BM}$ may result in the commercialisation of crowdfunding. The type of partnership suggested by S1RM between the major labels and already established and successful crowdfunding platforms would appear to suggest a reactive approach. However, in the Stage Two interviews with the major record label executives, one of them not only confirmed their partnership with PledgeMusic but also revealed initial experimentation into devising their own crowdfunding innovations. This 
is potentially significant in terms of paradigmatic shifts from reactive to proactive adoption strategies.

The interview data from the three stages of interviews also raised potentially significant points regarding how major label adoption of crowdfunding could impact upon the application of other user-centric BMs into their own operations. For instance, in the Stage One interviews, S1MM - who had over two years' experience researching and writing on consumer involvement in the music industry - hypothesised that "major labels [could] use crowdfunding platforms as part of their marketing strategy". This statement was echoed by the major label interviewee S2AS in the Stage Two interviews as he suggested that occasional crowdfunding campaigns could be used for a marketing community aspect. S2FB, another major label interviewee, also discussed how the adoption of crowdfunding could affect other aspects of their financial model. He mentioned one of their early stage innovations that involve incorporating crowdfunding into "very short window mini subscription service to the artist in the run up to the release of an album." This would suggest that the impact of crowdfunding on their marketing model may already be instigating its development by incorporating crowdfunding directly into its structure. These findings are particularly interesting as they demonstrate that, despite the ongoing prejudices from various interviewees against the major labels, they are displaying clear signs of innovative approaches to integrating crowdfunding into various configurations of their BMs.

In the Stage One interviews, S1CS proposed that the major record labels are already using crowdfunding, and that their reasons are actually based on compatibility factors with the pre-sell aspect of it. This viewpoint supports a recent academic journal article by Bannerman (2013) in which she stated that crowdfunding "can be combined with traditional industry models" (p. 14). This aspect of compatibility was also raised in the Stage Two interviews with the major label representatives. S2KS stated that their own 
BM is compatible with crowdfunded acts, and that they can therefore still provide services to them. However, he clarified that they were not operating a direct adoption strategy with crowdfunding but merely embracing the model indirectly through mutual complementary services - this adheres to a more reactive approach to crowdfunding.

None of the reviewed academic literature discussed how the major record labels would be affected by incorporating indirect embracement of crowdfunding into their own BMs. In the Stage One interviews, S1RT stated that the major labels indirectly use crowdfunding by observing artist success rates (in terms of financial achievements and number of followers) as part of an A\&R strategy. He suggested that this benefits the labels by making the A\&R process easier, although it could also be considered a reactive approach that adheres to the risk mitigation strategies discussed above.

The aspect of negative organisational approaches to crowdfunding, or its impact on major labels who have not directly adopted it into their BM, has received minimal attention in the academic literature. One exception is a recent article by Bannerman (2013) in which she described crowdfunding as "a model that can loosen links between creators and stable sources of funding and professional resources" (p. 29). Therefore, the discussion of these themes by the companies across all three stages of the interviews may represent new research ground. In the Stage Two interviews with the senior executives from the major record labels, two of them stated that they would not use crowdfunding in their BM; however, these two interviewees were from the same two major record labels whose other interviewed senior executives stated that they were incorporating direct or indirect adoption strategies for crowdfunding. Therefore, there appears to be a lack of unity and clarity across senior management levels within the major labels regarding their official stance on crowdfunding adoption strategies. This was confirmed by the rationales for why the major labels were not using crowdfunding, in which S2AS admitted to lacking expertise on the extent of the label's involvement with crowdfunding. 
Other major label interviewees provided opinions into the reasons for nonadoption strategies of crowdfunding by the major record labels. For instance, S2JH argued that, because their BM is geared towards business-to-business ventures and not business-to-consumer, any funding campaigns that they would operate would be conducted with other companies. His phrasing, in that he specifically stated that the prospect of them talking down to the consumer level is unlikely, suggested a rigidly hierarchical structure that precludes any direct bi-directional interactions with end consumers. One last viewpoint, from S2KS, was that they would neither embrace nor combat crowdfunding as they did not consider it a threat to their BM. However, this statement was contradicted in the Stage Three follow-up interview with S1FG in which he maintained that the major labels should be concerned over the shift in financial control to the artists through crowdfunding platforms. However, the crowdfunding interviewee S1RG expressed in his Stage Three follow-up interview that, based on the information provided regarding the label involvement with crowdfunding, he was no longer confident that they are still concerned over the impact of crowdfunding on them. He still maintained a historic concern and suggested that the reaction of the labels to crowdfunding is in itself an admission of its significance for the industry.

In his Stage One interview, S1FG expressed that the major record labels would actually attempt to combat crowdfunding through the provision of more creative freedom for their own artists in order to reduce negative perceptions. Although this proposed repel approach of actively attempting to combat crowdfunding was not supported in any other interview, it nevertheless could instead be considered as an example of forced adaptation by the labels.

\subsection{Impact of crowdfunding on live sector companies' business models}


S1RG, who is based in Australia, described how live music crowdfunding has recently grown exponentially in popularity in certain concentrated geographic localities such as Australia. However, he suggested that it has not reached global exposure yet on account of a lack of platforms providing services for the consumers. This viewpoint was reflected in the Stage Two interview with $\mathrm{S} 2 \mathrm{CC}$ in which he claimed that already existing production agencies are currently being outsourced to produce crowdfunded shows instead of utilising new crowdfunding platforms. This therefore implies that live music crowdfunding is not an innovation that is driven by the consumers on account of the need for firms to proactively facilitate new technological platforms for consumer involvement. The subcontracting of this crowdfunding to production agencies and the lack of start-ups may be impeding its potential.

In his Stage Three interview, S1RG - who reiterated his previous comments that his personal experience of major event companies was that they were actively resisting innovation that involves consumers, later remembered that he had encountered one that was actually taking a proactive approach to involving them by pushing their BM boundaries with regard to new revenue models. This viewpoint is potentially significant as it demonstrates polarising approaches by different major event companies.

S1EO - who had over one year's experience of live sector crowdfunding expressed in his Stage One interview that crowdfunding of live events would grow in importance for both artists and promoters - whom he suggested will eventually realise the logic of incorporating crowdfunding into their own BM. In the Stage Three followup interviews, S1RG - who have three years' experience of hosting a live crowdfunding platform - reflected the previous opinions regarding the rise of live crowdfunding out of negligibility in the future. However, he also commented on the scale and complexity factor influencing whether or not promoters should use crowdfunding. His rationale was that large-scale events such as festivals could not be purely crowdfunded in the near future 
- suggesting that the simplicity of the user interface may prove to be a key feature for music industry firms to develop crowdfunding platforms for live events.

Another interviewee also suggested an opportunity for the live sector that ties in with the previous sub-theme relating to crowd-sourced gigs by commenting that "something that is becoming popular and I think is going to grow is the idea of doing smaller, more intimate shows in non-standard venues. So, in a person's home for example.” However, he also acknowledged the substantial amount of challenges associated with these nonstandard venue events that include noise level complaints associated with certain music genres.

\section{Conclusions}

This research paper has sought to cover new research ground by exploring the predominantly untapped topic area of how rewards-based crowdfunding is affecting the development of BMs for the music industry stakeholder groups of independent artists, major labels and live sector organisations. As a result of the initial literature reviews, combined with the empirical results and analytical discussion, conclusions can now be drawn in relation to the three proposed research questions for this study.

\subsection{Conclusions for research question 1: How is crowdfunding in the music industry} affecting the ways in which key stakeholder groups approach and develop their financial models?

The findings of this study suggest that rewards-based crowdfunding can provide substantial associated benefits for the financial model of independent artists due to the enhancement of direct revenue instability resolutions. However, these attributes are dependent on fan base demographic variables relating to age group and genre due to sustained apprehension from younger audiences or those who exhibit rap or hip hop 
genres preferences. Artists can benefit from crowdfunding in terms of deriving freedoms to allocate crowdfunding capital as they see fit as the artists do not have to share their proceeds with the label. Although crowdfunding generally does not generate profits for the artists' financial model as their budget is normally only higher than the target capital in order to take into account credit card commissions, taxes and other contingency costs, nevertheless they can accrue higher funds for projects due to bypassing label commissions and therefore can achieve financial success indirectly as a result of superior product/service offerings. For tour-based crowdfunding, financial motivations for touring revenue will drive development for the artists, while the geographic locality of the crowdfunded events will motivate financial contributions from the fans. Ultimately, the artists' innovation opportunities for crowdfunding depend both on internal dependency factors (i.e. artist skills and abilities in the areas of PR, marketing and finance) as well as external dependency factors (i.e. social media connectedness, Internet technologies and consumer demographics).

The findings also suggest that the major record labels are currently using crowdfunding to various degrees on account of compatibility factors with the pre-sell aspect. The adoption of crowdfunding by the major record labels could also affect other aspects of their financial model such as the prospect of incorporating crowdfunding into mini subscription services to the artist in the lead up to an album release. These findings demonstrate that, despite the ongoing prejudices from various interviewees against the major labels, they are displaying clear signs of innovative approaches to integrating crowdfunding into various configurations of their BMs.

5.2 Conclusions for research question 2: What are the crossover implications of these consumer-driven financial model developments on other associated operational models of the stakeholders? 
The findings of this study suggest that rewards-based crowdfunding, if implemented appropriately, can facilitate beneficial crossover implications for the marketing model of artists by helping them to leverage their brand and to achieve previously unachievable goals such as live events or tours. It can also provide benefits through transcendence into interpersonal artist-fan relationships with positive perceptions of sharing gestures and interactions. As shown by the direction of influence arrows in Figure 2, these interpersonal relationships can become negative and destructive if not correctly implemented or fulfilled. This can have crossover implications for the artists' financial model as a lack of consumer confidence can result in unsustainability of the crowdfunding model. However, the current study concludes that these potential negative associations are somewhat offset by the sustainability associations of the financial freedoms of crowdfunding for the artists. These financial freedoms not only feed into financial benefits depending on budgeting, marketing and brand knowledge of the artists, but also exhibit crossover influences on their production model by enabling the attainment of otherwise unachievable live event production.

The findings also suggest that crowdfunding is affecting the major labels not in terms of their financial model but in the involuntary adaptation of their marketing model to become more creative, resilient and artist-friendly. Furthermore, major label alterations to their marketing model in terms of re-envisioning artist relationships are a result of crossover implications from the financial independence to the financial model of artists due to crowdfunding as mentioned above, as well as implications from the production model of the artists due to their creative freedoms and therefore superior musical output. The major labels also indirectly use crowdfunding by observing artist success rates (in terms of financial achievements and number of followers) as part of an A\&R strategy which makes the process easier to manage. 
5.3 Conclusions for research question 3: What future adaptation strategies should these industry stakeholders, organisations or sectors take in order to maximise the efficiency of their user-centric business model innovations?

The findings of this study suggest that artists must incorporate ethical awareness into their future crowdfunding endeavours so that consumers are not being manipulated on account of their increasingly young age and associated immaturity with financial management. Ethical exploitation from artists can lead to negative consequences for not only the artist's marketing model and career building but also for the sustainability of crowdfunding itself. In order to maximise the innovative potential for artists using crowdfunding they must also develop the skills and abilities to manage related business activities such as PR, marketing and end-sales taxes. For future live sector crowdfunding, artists should adapt their BMs to overcome the challenges of building a large enough network of fan-investors to maintain a sustainable revenue model and should work with already existing networks to increase time and work efficiency.

The findings also suggest that the type of partnership between the major labels and already established and successful crowdfunding platforms reflects a reactive approach to this financial model of user-centric innovation. However, evidence of initial experimentations of the some of the major labels into devising their own crowdfunding innovations suggests a paradigmatic shift from a reactive to a proactive adoption strategy from the major record labels. Their adoption of crowdfunding could also potentially impact upon the application of other user-centric BMs into their own business practices. They could also use crowdfunding platforms as part of their marketing strategy and the adoption of crowdfunding could affect other aspects of their financial model. They are now considering a more user-centric financial $\mathrm{BM}$ as an innovation strategy, and the impact of crowdfunding on their marketing model may already be initiating its 
development in terms of creativity, strength and artist relations by incorporating crowdfunding directly into its structure.

The findings additionally suggest that already existing live event production agencies are presently being outsourced to create crowdfunded shows as opposed to using new crowdfunding platforms. Live music crowdfunding is not an innovation that is driven by the consumers because of the need for companies to proactively facilitate new technological platforms for user involvement. The subcontracting of this crowdfunding to production agencies and the lack of start-ups may be impeding its potential.

\subsection{Implications for theory}

This study has been exploratory and theory-building in nature; therefore every stage of the project has endeavoured to address areas that have received little or no attention from academic literature reviews and empirical studies in order to cover new research ground. The findings therefore may have implications for developing new theories surrounding the influence of crowdfunding with various industry sectors and the subsequent BM development surrounding its integration in various industry orientations. In particular, the conceptual model in Figure 2 may represent the foundation of new theoretical development for music industry research as it demonstrates the complexities and interrelatedness of crowdfunding influence on industry stakeholder BMs to an extent not covered by previous research studies. When considering that the initial review of music industry crowdfunding in the existing literature revealed a lack of theoretical development in relation to how crowdfunding is effectively re-shaping the music industry in terms of industry stakeholders, BMs and sector landscapes, the theoretical contribution of the current study through its qualitative, empirical exploration and analysis becomes apparent. 


\subsection{Implications for practitioners}

Due to the pragmatic nature of this research study, the findings may have substantial implications for practitioners beyond the three studied industry stakeholder groups. The fact that this study involved in-depth interviews with both small-scale and major firms in the artist management and live sector groups indicates that these findings will provide insights for them regarding each other's relationships with consumer involvement and crowdfunding innovations within the music industry. This aspect may benefit their future partnership opportunities with each other or other internal / external stakeholders as it could facilitate coopetition strategies based on mutual understanding and compatibility.

In terms of specific implications, artist management companies may benefit from the findings in relation to the revenue stability implications of crowdfunding on the artists and the associated dependency variables - they could use this information to adapt their business models in terms of how they support the artists and derive their own indirect revenue through them. Furthermore, the findings relating to the capacity in which major labels are starting to incorporate crowdfunding and the indirect effect on their marketing strategies may be of benefit to independent labels which operate as subsidiaries to the major labels or are in competition with them. The insights into the practicalities of the integration for the major labels and their shifting attitude towards it may provide the independent labels with direction into how they could adapt their own marketing models to offer the artists alternative opportunities, as well as how their own financial models may be applicable to incorporating crowdfunding directly in a way in which the major labels cannot achieve. Lastly, the findings in relation to live sector crowdfunding, and how artists are advised to maintain existing networks, may benefit promoters, stage crews and sponsors as they can then take steps to adapting their own business models to accommodate both a slower turnover rate of artists and the integration of crowdfunding elements into their live sector production processes. Moreover, as the findings indicate 
that crowdfunding innovations in the live sector are not driven by the consumers presently, these insights may provide some stability for these associated companies as they direct their crowdfunding platform compatibility in line with the artists' specifications.

This study does not argue to have facilitated empirical generalisation of the findings and conclusions on account of the fact that it did not proclaim to address the entire music industry or every industry stakeholder. Nevertheless, the above statements show the applicability of the findings to certain associated stakeholders within the industry. This study does, therefore, argue to have facilitated theoretical generalisation as other external industries and organisations have a level of applicability and compatibility with the current research study. This extends beyond research opportunities as these firms could actively adapt their own BMs and innovation strategies to become more usercentric and adapt their approaches to crowdfunding platforms to become more reactive or proactive by learning from how music industry stakeholders are being affected by and reacting to - the increase in crowdfunding integration into industry BMs. The concept of a user-centric financial model for practitioners is especially applicable to other industries and sectors as crowdfunding is becoming increasingly ubiquitous throughout both creative and non-creative industries.

\subsection{Suggestions for further research}

The current study appears to have addressed several sub-topics that have not been covered by previous research; these sub-topics include negative organisational approaches to crowdfunding and the impact of crowdfunding on labels who have not directly adopted it into their BM. Further research could empirically test the findings in relation to these topics through a comparative analysis with other industry stakeholders. The overall topic of this research study has also not been adequately addressed in other research studies; 
therefore further research could take the conceptual framework in Figure 2 and use it as a starting point from which to explore other industries in terms of how crowdfunding is affecting the BMs of different industry sectors, groups or individual stakeholders.

There are opportunities to expand this study to include various other stakeholders within the music industry. The present study only concentrated on independent artists, major labels and live sector companies because these were identified as germane to the topic. However, further studies could explore other related stakeholders such as major label artists, independent record labels and other industry players such as publishers, distributors or management companies.

The conclusions drawn from this study could also be used as starting points from which to conduct comparative empirical studies with other creative industries. For instance, one report suggested that direct revenue instability with current creative industry BMs represents an issue that could be addressed by a research study. The current study concluded that rewards-based crowdfunding can provide substantial benefits for the financial model of independent music artists due to the enhancement of direct revenue instability resolutions. Subsequently, empirical research into the revenue instability resolution of rewards-based crowdfunding on the BMs of other creative industries or other types of artists (for instance visual or performing artists) would be advantageous for developing the theoretical foundations that the current paper has initiated for this research field.

\subsection{Limitations}

Like all research articles, the current paper was subject to a number of limitations relating to practical resources, time allocation and word count restrictions that have resulted in decisions to concentrate this study on certain aspects of the research domain and not consider (or only briefly consider) other aspects. These are concisely detailed below. 
Through the literature review into music industry BMs it was determined that any attempt to study an overall BM framework for the entire music industry would prove too vast for any small-scale research project. Instead, the literature review of business modelling and crowdfunding assisted in identifying three contextually relevant BMs from which the research study would be focussed. Due to these limitations, the conclusions do not exhibit empirical generalisation as the study did not claim to holistically address the $\mathrm{BM}$ of the entire industry or the implication for every individual stakeholder. Instead, the conclusions have theoretical generalisation implication for external industries or stakeholder as discussed in the above section on implications for practitioners.

This paper also discussed the population of the study to be targeted with the indepth interviews over the course of the three-stage interview process. It was determined that it would be inconceivable to speak to representatives from all stakeholders of the music industry and still maintain a high level of research depth and quality. This limitation has had implications for the generalisability of the research findings as discussed above. It was also decided that, due to time and resource limitations, only five representatives from each of the three identified stakeholder groups would be interviewed in Stage Two, and only eight of the Stage One interviewees would be interviewed again in the Stage Three follow-up interviews. Although these sample sizes were significantly smaller than the thirty four music industry experts who were interviewed in Stage One, it provided an overall sample size of fifty seven interviews that was more than adequate for producing the required depth and breadth of high quality research data for the study.

Lastly, this paper took the strategic decision to only concentrate on rewards-based crowdfunding on account of the lack of associated theoretical development on this crowdfunding typology in the music industry literature despite its rise in growth and popularity over the past twenty years. As described by Griffin (2012), the crowdfunding sector actually consists of several other models such as the donation model (where 
contributors receive nothing), the lending model (also known as peer-to-peer lending) and the equity model (where contributors gain a share of profits or other return on their investment). Future studies may wish to explore these crowdfunding models in terms of similar industry and stakeholder contexts.

\section{References}

Agrawal, A., Catalini, C. and Goldfarb, A. (2011) Friends, family, and the flat world: The geography of crowdfunding. NBER Working Paper 16820 pp 1-61

Al-Debei, M.M. and Avison, D. (2010) Developing a unified framework of the business model concept. European Journal of Information Systems 19 (3) pp 359-376

Allard-Poesi, F. (2005) The paradox of sensemaking in organizational analysis. Organization 12 (2) pp 169-196

Arewa, O.B. (2010) YouTube, UGC, and digital music: Competing business and cultural models in the internet age. Northwestern University Law Review 104 (2) pp $431-476$

Arts Council (2010) Digital Audiences - Engagement with Arts and Culture Online. November 2010 pp 1-65

Bannerman, S. (2013) Crowdfunding culture. Journal of Mobile Culture 7 (1) pp 1-30

Belleflamme, P., Lambert, T. and Schwienbacher, A. (2013) Individual crowdfunding practices. Venture Capital 15 (4) pp 313-333

Bourreau, M., Gensollen, M. and Moreau, F. (2012) The impact of a radical innovation on business models: Incremental adjustments or big bang? Industry \& Innovation 19 (5) pp 415-435

Buff, L.A. and Alhadeff, P. (2013) Budgeting for crowdfunding rewards. Journal of the Music \& Entertainment Industry Educators Association 13 (1) pp 27-44

Cardoso, A. and Ramos, I. (2012) Looking at the past to enrich the future: A reflection on klein and myers' quality criteria for interpretive research. Electronic Journal of Business Research Methods 10 (2) pp 77-88

Casadesus-Masanell, R. and Hervas-Drane, A. (2010) Competing against online sharing. Management Decision 48 (8) pp 1247-1260 
Cavalcante, S., Kesting, P. and Ulhøi, J. (2011) Business model dynamics and innovation: (re)establishing the missing linkages. Management Decision 49 (8) pp $1327-1342$

CCS (2011) The Music Blueprint. March 2011 pp 1-60

Chaney, D. (2012) The music industry in the digital age: Consumer participation in value creation. International Journal of Arts Management 15 (1) pp 42-52

Chesbrough, H. (2006) Open business models: How to thrive in the new innovation landscape.Harvard : Harvard Business Press.

Choi, H. and Burnes, B. (2013) The internet and value co-creation: The case of the popular music industry. Prometheus 31 (1) pp 35-53

DeCuir-Gunby, J.T., Marshall, P.L. and McCulloch, A.W. (2011) Developing and using a codebook for the analysis of interview data: An example from a professional development research project. Field Methods 23 (2) pp 136-155

Demil, B. and Lecocq, X. (2010) Business model evolution: In search of dynamic consistency. Long Range Planning 43 (2/3) pp 227-246

Dewenter, R., Haucap, J. and Wenzel, T. (2012) On file sharing with indirect network effects between concert ticket sales and music recordings. Journal of Media Economics 25 (3) pp 168-178

Doganova, L. and Eyquem-Renault, M. (2009) What do business models do?: Innovation devices in technology entrepreneurship. Research Policy 38 (10) pp 15591570

Doz, Y.L. and Kosonen, M. (2010) Embedding strategic agility: A leadership agenda for accelerating business model renewal. Long Range Planning 43 (2/3) pp 370-382

Dubosson-Torbay, M., Osterwalder, A. and Pigneur, Y. (2002) E-business model design, classification, and measurements. Thunderbird International Business Review 44 (1) pp 5-23

Ericsson, S. (2010) Recorded music industry and the emergence of online music distribution: Innovation in the absence of copyright (reform), the. Geo.Wash.L.Rev. 79 pp 1783

Gamble, J.R. and Gilmore, A. (2013) A new era of consumer marketing? An application of co-creational marketing in the music industry. European Journal of Marketing 47 $(11 / 12)$ pp 1859-1888

Generator (2011) Generator Annual Report 2011. 20111-26

George, G. and Bock, A.J. (2011) The business model in practice and its implications for entrepreneurship research. Entrepreneurship: Theory \& Practice 35 (1) pp 83-111

Grant, M.A., Rohr, L.N. and Grant, J.T. (2012) How informants answer questions? implications for reflexivity. Field Methods 24 (2) pp 230-246 
Griffin, Z.J. (2012) Crowdfunding: Fleecing the American masses. Case W.Res.JL Tech.\& Internet 4 (2) pp 375-410

Harhoff, D., Henkel, J. and von Hippel, E. (2003) Profiting from voluntary information spillovers: How users benefit by freely revealing their innovations. Research Policy 32 (10) pp 1753-1769

Harris, S. (2000) Reconciling positive and interpretative international management research: A native category approach. International Business Review 9 (6) pp 755-770

Herstatt, C. and Schweisfurth, T. (2014) The intellectual pillars of user innovation: A co-citation analysis. Technologie- und Innovationsmanagement, Technische Universität Hamburg-Harburg Working Paper No. 87 (1) pp 17

IFPI (2013) IFPI Digital Music Report 2013: Engine of a digital world. pp 1-36

Izvercian, M. and Alina Seran, S. (2013) The Web 2.0 and the globalization impact on new consumer emergence and classification. In: Anonymous 2013 International Conference on Education, Management and Social Science (ICEMSS-13). 22nd August 2013 Tianjin, China. Atlantis Press, pp 158-161

Kallio, J., Tinnila, M. and Tseng, A. (2006) An international comparison of operatordriven business models. Business Process Management Journal 12 (3) pp 281-298

Kappel, T. (2009) Ex ante crowdfunding and the recording industry: A model for the us. Loyola Of Los Angeles Entertainment Law Review 29 (3) pp 375-385

Knox, K. (2003) A Researcher's dilemma-philosophical and methodological pluralism. Electronic journal of business research methods 2 (2) pp 145-154

Kunze, O. and Mai, L.W. (2007) Consumer adoption of online music services: The influence of perceived risks and risk-relief strategies. International Journal of Retail \& Distribution Management 35 (11) pp 862-877

Leech, N.L. and Onwuegbuzie, A.J. (2007) An array of qualitative data analysis tools: A call for data analysis triangulation. School Psychology Quarterly 22 (4) pp 557-584

Lehner, O.M. (2013) Crowdfunding social ventures: A model and research agenda. Venture Capital 15 (4) pp 289-311

Lincoff, B. (2008) Common sense, accommodation and sound policy for the digital music marketplace. Journal of International Media and Entertainment Law 2 (1) pp 1-64

Lüthje, C., Herstatt, C. and von Hippel, E. (2005) Userinnovators and "local" information: The case of mountain biking. Research Policy 24 (6) pp 951-965

Lysonski, S. and Durvasula, S. (2008) Digital piracy of MP3s: Consumer and ethical predispositions. Journal of Consumer Marketing 25 (3) pp 167-178

Mason, K. and Spring, M. (2011) The sites and practices of business models. Industrial Marketing Management 40 (6) pp 1032-1041 
McGrath, R.G. (2010) Business models: A discovery driven approach. Long Range Planning 43 (2) pp 247-261

Oestreicher, K.G. and Kuzma, J. (2009) The music industry \& its consumers: A potential divorce through technology and shifting market linkages? $\underline{\text { Chinese Business }}$

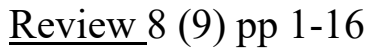

Ordanini, A., Miceli, L., Pizzetti, M. and Parasuraman, A. (2011) Crowd-funding: Transforming customers into investors through innovative service platforms. Journal of Service Management 22 (4) pp 443-470

Papies, D., Eggers, F. and Wlömert, N. (2011) Music for free? how free ad-funded downloads affect consumer choice. Journal of the Academy of Marketing Science 39 (5) pp 777-794

Parry, G., Bustinza, O.F. and Vendrell-Herrero, F. (2014a) Copyright and creation: Repositioning the argument. Strategic Direction 30 (3) pp 32-35

Parry, G., Vendrell-Herrero, F. and Bustinza, O.F. (2014b) Using data in decisionmaking: Analysis from the music industry. Strategic Change 23 (3-4) pp 265-277

Power, D. and Hallencreutz, D. (2007) Competitiveness, local production systems and global commodity chains in the music industry: Entering the US market. Regional Studies 41 (3) pp 377-389

Qu, S.Q. and Dumay, J. (2011) The qualitative research interview. Qualitative Research in Accounting and Management 8 (3) pp 238-264

Regner, T. and Barria, J.A. (2009) Do consumers pay voluntarily? the case of online music. Journal of Economic Behavior \& Organization 71 (2) pp 395-406

Rowlands, B.H. (2005) Grounded in practice: Using interpretive research to build theory. Electronic Journal of Business Research Methods 3 (1) pp 81-92

Sandberg, E., Kihlén, T. and Abrahamsson, M. (2011) Characteristics of a logisticsbased business model. Journal of Marketing Channels 18 (2) pp 123-145

Shafer, S.M., Smith, H.J. and Linder, J. (2005) The power of business models. Business Horizons 48 (3) pp 199-207

Sirkeci, I. and Magnúsdóttir, L.B. (2011) Understanding illegal music downloading in the UK: A multi-attribute model. Journal of Research in Interactive Marketing 5 (1) pp $90-110$

Soriano, J., Lizcano, D., Hierro, J.J., Reyes, M., Schroth, C. and Janner, T. (2008) Enhancing user-service interaction through a global user-centric approach to SOA. In: Anonymous Networking and Services, 2008. ICNS 2008. Fourth International Conference on. IEEE, 194-203.

Styvén, M.E. (2010) The need to touch: Exploring the link between music involvement and tangibility preference. Journal of Business Research 63 (9/10) pp 1088-1094 
Teece, D.J. (2010) Business models, business strategy and innovation. Long Range Planning $43(2 / 3)$ pp 172-194

von Hippel, E. (2007) Horizontal innovation networks: By and for users. Industrial and Corporate Change 16 pp 293-315

Warr, R. and Goode, M.M. (2011) Is the music industry stuck between rock and a hard place? the role of the internet and three possible scenarios. Journal of Retailing and Consumer Services 18 (2) pp 126-131

Zheng, H., Li, D., Wu, J. and Xu, Y. (2014) The role of multidimensional social capital in crowdfunding: A comparative study in china and US. Information \& Management 51 (4) pp 488-496

Zott, C. and Amit, R. (2010) Business model design: An activity system perspective. Long Range Planning 43 (2/3) pp 216-226 


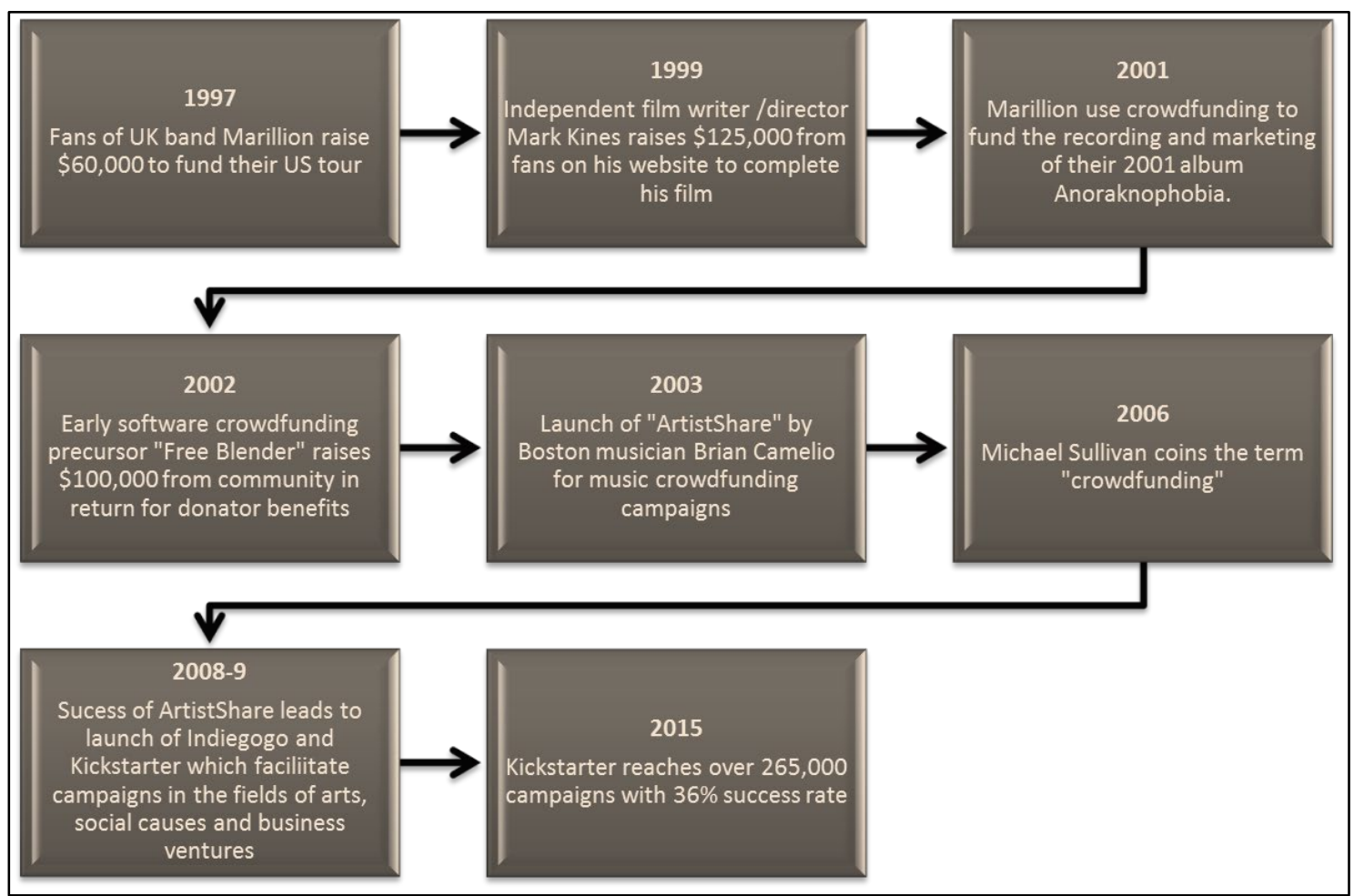

Figure 1 Key milestones in crowdfunding 1997 - 2015 (source: Wikipedia) 


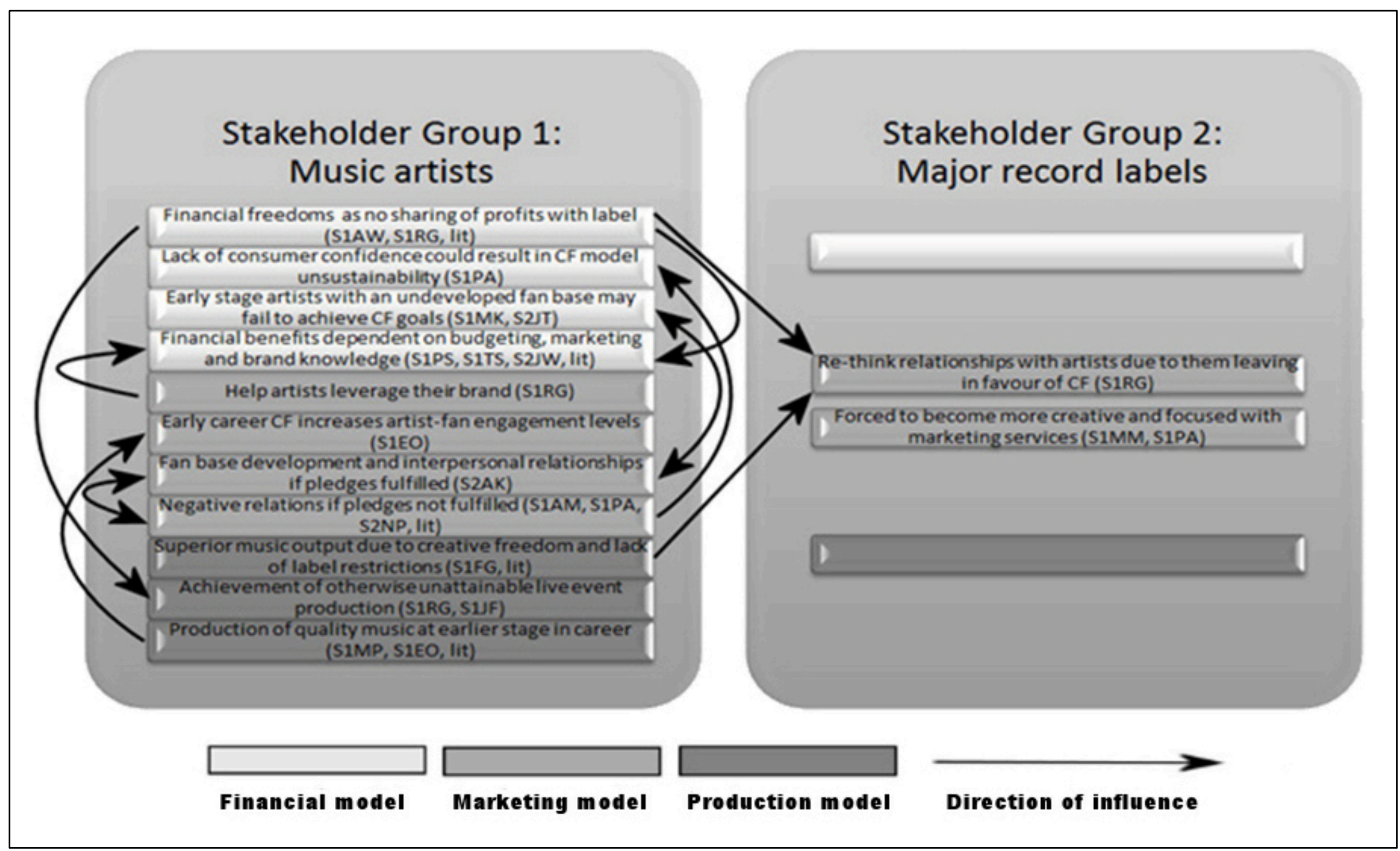

Figure 2 Impact of rewards-based crowdfunding on business models of industry stakeholders 